\title{
The Cloninger Type I/Type II Typology: Configurations and Personality Profiles in Socially Stable Alcohol Dependent Patients
}

\author{
Peter Wennberg, ${ }^{1}$ Kristina Berglund, ${ }^{2}$ Ulf Berggren, ${ }^{3}$ Jan Balldin, ${ }^{3}$ and Claudia Fahlke ${ }^{2}$ \\ ${ }^{1}$ Centre for Social Research on Alcohol and Drugs, Stockholm University, 10691 Stockholm, Sweden \\ ${ }^{2}$ Department of Psychology, University of Gothenburg, 40530 Gothenburg, Sweden \\ ${ }^{3}$ Department of Psychiatry and Neurochemistry, Institute of Neuroscience and Physiology, University of Gothenburg, \\ 41345 Gothenburg, Sweden \\ Correspondence should be addressed to Peter Wennberg; peter.wennberg@ki.se
}

Received 26 August 2014; Revised 28 November 2014; Accepted 7 December 2014; Published 17 December 2014

Academic Editor: Georges Brousse

Copyright (C) 2014 Peter Wennberg et al. This is an open access article distributed under the Creative Commons Attribution License, which permits unrestricted use, distribution, and reproduction in any medium, provided the original work is properly cited.

\begin{abstract}
Many attempts have been made to derive alcohol use typologies or subtypes of alcohol dependence and this study aimed at validating the type I/type II typology in a treatment sample of socially stable alcohol dependent males and females. A second aim was to compare the two types with respect to their temperament profiles. Data was part of a larger ongoing longitudinal study, the Gothenburg Alcohol Research Project, and included 269 alcohol dependent males and females recruited from three treatment centers. The results showed that type II alcoholism occurred as a more homogenous type than type I alcoholism, and type I alcoholism seemed too heterogeneous to be summarized into one single type. When adapting a strict classification, less than a third of the study population could be classified in accordance with the typology, suggesting that the typology is not applicable, at least in socially stable individuals with alcohol dependence. The results also showed that type II alcoholics showed higher levels of novelty seeking than did the individuals that were classified as type I alcoholics. Quite surprisingly, the individuals classified as type II alcoholics also showed higher levels of harm avoidance than did the individuals that were classified as type I alcoholics.
\end{abstract}

\section{Background}

As a means of understanding the high level of heterogeneity among individuals with alcohol use disorders (AUD) in terms of etiology and manifestations, many attempts have been made to derive alcohol use typologies or alcoholic subtypes. Although a great deal of effort has been put into this area of research, no generally accepted typology has yet been presented. As the concept is employed here, a typology refers to a set of fairly homogenous classes with respect to some specified characteristics. Belonging to any of these classes does not have to be a fixed and unchangeable feature but might be seen as a more or less temporary state in the context of a dynamic process (see a discussion in [1]). We believe that a good typology includes three basic features: (1) some form of face validity or heuristic power, (2) the types occur more frequently than would be expected if the criteria were randomly distributed across the subjects (i.e., the types form natural clusters), and (3) a majority (read more than 50 percent) of the subjects could be classified according to the typology in question.

In a study by Cloninger and colleagues [2] a population of 862 male adoptees was described in detail including data from temperance registers, child welfare agencies records, criminal records, and medical diagnoses. All in the study population were sons of single mothers and were adopted at an early age. The circumstance that the project had extensive information on the biological as well as the adoptive parents made it possible to single out the contribution of genetic from social heritage in the etiology of alcoholism. Furthermore, two quite different forms of alcoholism were also described as type I and type II alcoholism. While this study was based exclusively on males, another study by the same researchers [3] later added a female study population of 
adoptees. In summary, type I alcoholism includes influence of a childhood family environment, late-onset of alcohol-related problems (after age 25), men and women being affected equally, ability to abstain from drinking (at least temporarily), using alcohol as self-medication, and responding better to treatment. In summary, type II includes inheritance of the disease from the father, onset of alcohol-related problems before the age of 25 years, primarily males, inability to abstain from alcohol, history of antisocial acts, and poor response to treatment. In the present study we have focused on four key features to distinguish these types: gender, age of debut of alcohol-related problems, antisocial behavior, and paternal alcoholism. In addition to these features, the two types of alcoholism are also suggested to have different temperament profiles (Cloninger, 1987). [4] with higher levels of novelty seeking (NS) among type II alcoholics and higher levels of harm avoidance (HA) and reward dependence (RD) in type I alcoholics.

According to Cloninger et al. [4] the temperament traits are highly inherited personality traits that are underlined by specific neurotransmitters in the brain. The temperament traits are stable over time in contrary to the character traits, which are more determined by environmental factors and therefore less stable. In addition, the temperament traits are independently inherited of each other and therefore there are several combinations of them, which interact with several character profiles.

A study by Wills et al. [5] gave some support for the temperament profiles for type II alcoholics (high NS, low HA, and low RD). However, a review by Howard et al. [6] showed that NS was consistently associated with early onset alcohol abuse and antisocial behavior while the results regarding HA and $\mathrm{RD}$ were more inconsistent.

1.1. Aims. This study aimed at validating the Cloninger type I/type II typology (as described in $[2,3]$ ) in a treatment sample of socially stable (for definition, see Berglund 2009) alcohol dependent males and females. More specifically we aimed at (1) testing to what extent the most important characteristics were grouped together relative to chance in the two types and (2) how the two types differ with respect to their personality profiles.

\section{Methods}

This study was part of a larger ongoing longitudinal study (Gothenburg Alcohol Research Project-GARP) which aims to investigate the interaction between psychological, psychiatric, as well as neurobiological, and genetic characteristics in alcohol dependent individuals and also to evaluate whether these variables influence treatment outcome. The project has earlier been described in more detail [7-9].

2.1. Subjects. In this study, 269 individuals participated (61 females and 208 males), consecutively recruited from three different treatment centers in the western part of Sweden (two of which used 12-step programs $(n=192)$ and one of which used a psychosocial relapse prevention program $(n=77))$. Before inclusion in the study a psychiatric assessment was conducted and patients with severe psychiatric comorbidity were excluded. Participants included in the study met the diagnostic criteria for alcohol dependence as classified by DSM-IV [10]. In addition, three percent of the participants also met the DSM-IV criteria for other drug abuse/dependencies. The mean age of the subjects was $47.9 \pm$ 10.3 years (ranging from 21 to 71 years). Ninety-one percent had a permanent residence and $83 \%$ were employed for which reasons this group can be described as socially stable.

The recruitment procedure for inpatients and outpatients was somewhat different. Patients at an inpatient care unit were asked about participation in the project during the first week in treatment and if accepting interviewed 4-5 days later. In all, $65 \%$ of the inpatients agreed to participate. Outpatients were asked about participation during weeks 1-3 in treatment and if accepting interviewed one week later.

2.2. Procedure and Instruments. When arriving to treatment, the individuals were informed about the longitudinal study. Short thereafter they were interviewed by a trained interviewer from the research group. In addition, they also completed a number of psychological self-rating scales. As an interview instrument, the Addiction Severity Index (ASI [11]) was used. This interview assesses the following, on the basis of self-report, life-time, and recent severity of different lifedomains: family and social relationships, work and education, somatic symptoms, psychiatric symptoms, alcohol use, use of other drugs, and legal problems. ASI has acceptable reliability and validity $[12,13]$. Data on early debut, antisocial behavior, and paternal alcoholism was derived from the ASI. The indicator of debut before the age of 25 was defined as drinking until intoxication three times or more per week before that age. The indicator of antisocial behavior included prosecution for any of the following offences: violent crimes (robbery, assault, murder, or manslaughter), drug-related criminality, or drunken driving. The indicator of paternal alcoholism included answering yes to a question of whether the father had serious alcohol-related problems.

Personality was assessed by the Temperament and Character Inventory (TCI), a 238-item true-false self-rating questionnaire [14]. The TCI assesses four basic dimensions of temperament (novelty seeking (NS), harm avoidance (HA), reward dependence (RD), and persistence (PS)) and three dimensions of character (self-directedness (SD), cooperativeness (CO), and self-transcendence (ST)). The Swedish version of the TCI has earlier showed satisfactory psychometric properties for adults [15].

2.3. Data Processing and Analysis. A Configural Frequency Analysis $[16,17]$ was conducted with the purpose of finding specific configurations that were more frequent ("types") or less frequent ("antitypes") than expected by chance. We hypothesized that two specific configurations would come up as typical for type I: being a man or woman with late debut of alcohol problems and without signs of antisocial behavior or paternal alcoholism. Further, we hypothesized that one 
specific configuration would come up as typical for type II: being a man with early debut of alcohol problems, debut with signs of antisocial behavior, and paternal alcoholism.

Next, a crude classification was made to group the individuals in the sample into the two types. This was done by counting criteria (gender, age of debut, antisocial behavior, and paternal alcoholism). Subjects with equal number of type I/II criteria were defined as type I. A more strict classification was also done which only included subjects that fulfilled all the criteria for the respective type. Thereafter the personality profiles according to the TCI were compared between the classified types. Since the results include multiple statistical tests, significant results on the $5 \%$ level should be interpreted with caution.

\section{Results}

The first analysis of the 269 subjects included a test of whether the indicators of type I and type II, respectively, form naturally occurring configurations. This was done by including four important features of the types into a Configural Frequency Analysis. We hypothesized that three configurations would come out as more frequent than expected by chance: male gender, early debut of alcohol problems, antisocial behavior, and paternal alcoholism (type II); male gender, late debut of alcohol problems, no antisocial behavior, and no paternal alcoholism (type I); and female gender, late debut of alcohol problems, no antisocial behavior, and no paternal alcoholism (type I). While the configuration that indicates type II alcoholism came out as a significant type $(P=0.007)$, neither of the two configurations that would constitute type I alcoholism occurred more frequently than expected by chance. One configuration also came out as antitypical (i.e., occurring less frequently than expected by chance), namely, being male, with late debut of alcohol problems, antisocial behavior, and paternal alcoholism $(P=$ 0.02). However, one configuration that resembled type I came out as statistically significant (female, late debut of alcohol problems, no antisocial behavior, and paternal alcoholism; $P=0.008$ ). In all, 85 subjects out of 269 (i.e., 31.6 percent) could be defined as either type I or type II by the definitions used in this study. See Table 1.

Next, a crude classification was made of the two types, contingent of the number of criteria each subject fulfilled. Based on this classification 192 subjects (or 71.4 percent) were classified as type I and 77 subjects were classified as type II (or 28.6 percent). These two types were thereafter compared with respect to their temperament and character profile on the TCI. While there were no statistically significant differences between the two types with regard to their temperament profile, there were several differences in their character profile. While type I group had higher levels of self-directedness $\left(F_{(1,216)}=7.1 ; P=0.008\right)$ and cooperativeness $\left(F_{(1,216)}=4.1 ; P=0.043\right)$, type II group showed higher levels of self-transcendence $\left(F_{(1,216)}=5.6\right.$; $P=0.019)$. When including all temperament and character traits as independent continuous variables and type (I or II) as dependent one in a logistic regression (Nagelkerke $R^{2}=$ .087), only self-transcendence remains statistically significant $(P=0.046)$. See Figures $1(\mathrm{a})$ and $1(\mathrm{~b})$.

While this classification above forced all subjects into any of the two types only a minority could be classified as more strictly defined type I's or more strictly defined type II's. More specifically, 62 subjects fulfilled all the criteria for type I and 23 subjects fulfilled all criteria for type II. When the temperament and character profiles were compared between these two more strictly defined types, type II group came out as more prone to novelty seeking $\left(F_{(1,73)}=6.5 ; P=0.013\right)$ and, quite surprisingly, more harm avoidant $\left(F_{(1,73)}=6.1\right.$; $P=0.016)$. Furthermore, the pattern regarding character differences was similar to that in the previous analysis.

\section{Discussion}

This study aimed at examining to what extent type I and type II alcoholism exists as natural clusters and the personality profiles associated with these types. In our results, type II alcoholism occur as a more homogenous type than type I alcoholism and type I alcoholism was too heterogeneous as a phenomenon to be summarized into one single type. Furthermore, it should be noted that less than a third of the study population could be classified in accordance with the typology. This latter finding raises the possibility that this typology is not applicable to socially stable or socially well-preserved alcoholics. If so, this hampers the use of this typology since this group may comprise the majority of alcohol dependent individuals (see Berglund 2009 and references therein).

Our results give support to other typologies that distinguish between different forms of late onset alcoholism. One such example is the typology suggested by Zucker [18, 19] including four types and distinguishing between two late onset types (negative effect alcoholism that includes depression or anxiety) and developmentally cumulative (also labeled "primary alcoholism" without severe comorbidity other than the consequences of the alcohol disorder).

Quite according to theory, individuals that fulfilled the criteria for type II showed higher levels of novelty seeking than did the individuals that were classified as type I alcoholics. However, quite surprisingly, the individuals classified as type II alcoholics also showed higher levels of harm avoidance than did the individuals that were classified as type I alcoholics. This is in line with the overview by Howard et al. [6] stating that the results linking high levels of novelty to type II alcoholism are more consistent than results linking low levels of harm avoidance and reward dependence to type II. Furthermore, not to our surprise, type I alcoholics showed higher levels of self-directedness and cooperativeness and lower levels of self-transcendence than type II alcoholic.

While we believe that this study is relevant and employs a novel methodological approach, it also has some limitations. The main limitation concerns the representativeness of our sample of treatment seeking and, to some degree, socially well-adjusted alcohol dependent individuals. Although treatment seeking individuals often display severe psychiatric 
TABle 1: Prevalence of different configurations and their relative probability $(n=269)$.

\begin{tabular}{|c|c|c|c|c|c|c|c|}
\hline \multirow[b]{2}{*}{ Gender } & \multicolumn{3}{|c|}{ Configuration } & \multirow[b]{2}{*}{ Obs. freq. } & \multirow[b]{2}{*}{ Exp. freq. } & \multirow[b]{2}{*}{$P$ (bin. prob.) } & \multirow[b]{2}{*}{ Sign type/antitype } \\
\hline & $\begin{array}{c}\text { Early debut } \\
(<25 \mathrm{yrs})\end{array}$ & $\begin{array}{l}\text { Antisocial } \\
\text { behavior }\end{array}$ & $\begin{array}{l}\text { Paternal } \\
\text { alcoholism }\end{array}$ & & & & \\
\hline Male & Yes & Yes & Yes & 23 & 13.1 & 0.007 & Type \\
\hline Female & Yes & Yes & Yes & 4 & 3.8 & Ns & \\
\hline Male & No & Yes & Yes & 11 & 20.1 & 0.02 & Antitype \\
\hline Female & No & Yes & Yes & 2 & 5.9 & Ns & \\
\hline Male & Yes & No & Yes & 22 & 24.4 & Ns & \\
\hline Female & Yes & No & Yes & 8 & 7.2 & Ns & \\
\hline Male & No & No & Yes & 33 & 37.5 & Ns & \\
\hline Female & No & No & Yes & 20 & 11.0 & 0.008 & Type \\
\hline Male & Yes & Yes & No & 17 & 15.6 & Ns & \\
\hline Female & Yes & Yes & No & 2 & 4.6 & Ns & \\
\hline Male & No & Yes & No & 31 & 23.9 & Ns & \\
\hline Female & No & Yes & No & 4 & 7.0 & Ns & \\
\hline Male & Yes & No & No & 23 & 28.9 & Ns & \\
\hline Female & Yes & No & No & 7 & 8.5 & Ns & \\
\hline Male & No & No & No & 48 & 44.5 & Ns & \\
\hline Female & No & No & No & 14 & 13.1 & Ns & \\
\hline
\end{tabular}

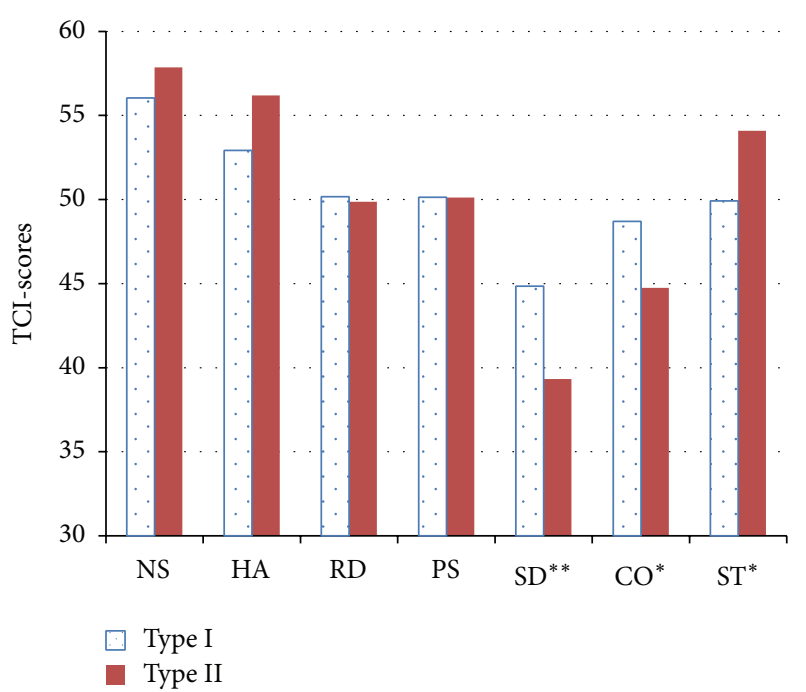

(a)

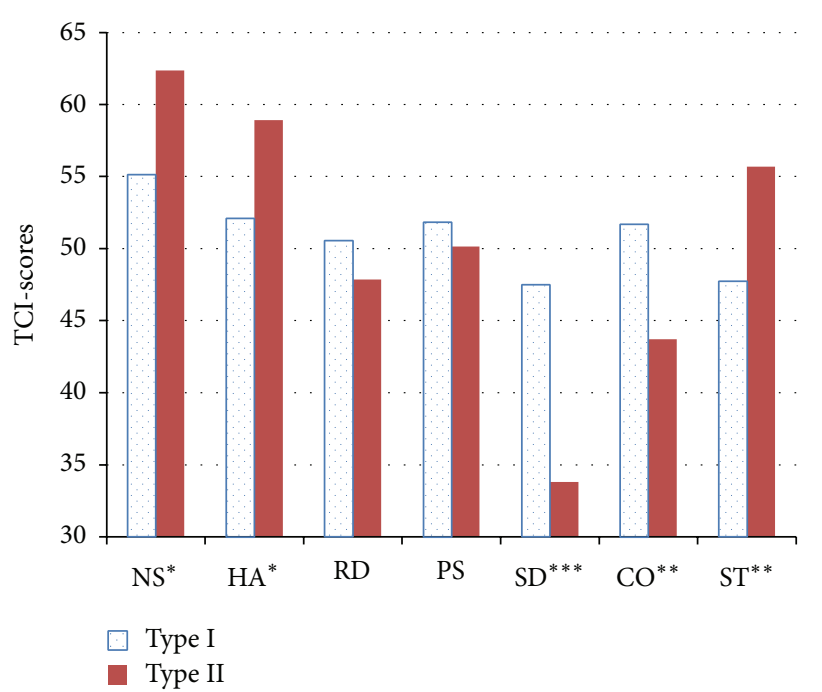

(b)

Figure 1: (a) Temperament and character profiles for the type I and type II alcoholics $(n=218) .{ }^{*} P<0.05 ;{ }^{* *} P<0.01$; NS = novelty seeking, $\mathrm{HA}=$ harm avoidance, $\mathrm{RD}=$ reward dependence, $\mathrm{PS}=$ persistence, $\mathrm{SD}=$ self-directedness, $\mathrm{CO}=$ cooperativeness, and $\mathrm{ST}=$ self-transcendence. (b) Temperament and character profiles for the strictly defined type I and type II alcoholics $(n=75) .{ }^{*} P<0.05 ;{ }^{* *} P<0.01$; ${ }^{* * *} P<0.001$; $\mathrm{NS}=$ novelty seeking, $\mathrm{HA}=$ harm avoidance, $\mathrm{RD}=$ reward dependence, $\mathrm{PS}=$ persistence, $\mathrm{SD}=$ self-directedness, $\mathrm{CO}=$ cooperativeness, $\mathrm{ST}$ = self-transcendence.

comorbidity, we have in the present study excluded patients with severe psychiatric comorbidity and therefore the level of comorbidity in this sample is lower than in the general alcohol dependent population. Further, while we have extensive data for every individual in the study, the sample size is relatively small.
Studies on alcohol typologies call for an integration of finding from genetics, personality, and social psychology into a developmental model. To be valuable as an intellectual tool, typologies should also be clinically relevant. Future research within this project will focus on the validity of other common alcohol typologies and an examination of 
the clinical relevance of these typologies in terms of treatment outcome.

\section{Conflict of Interests}

The authors declare that there is no conflict of interests regarding the publication of this paper.

\section{References}

[1] L. R. Bergman, "The application of a person oriented approach: types and clusters," in Developmental Science and the Holistic Approach, L. R. Bergman, R. B. Cairns, L.-G. Nilsson, and L. Nystedt, Eds., pp. 137-154, Lawrence Erlbaum Associates, Mahwah, NJ, USA, 2000.

[2] C. R. Cloninger, M. Bohman, and S. Sigvardsson, "Inheritance of alcohol abuse. Cross-fostering analysis of adopted men," Archives of General Psychiatry, vol. 38, no. 8, pp. 861-868, 1981.

[3] M. Bohman, S. Sigvardsson, and C. R. Cloninger, "Maternal inheritance of alcohol abuse: cross-fostering analysis of adopted women," Archives of General Psychiatry, vol. 38, no. 9, pp. 965969, 1981.

[4] C. R. Cloninger, S. Sigvardsson, and M. Bohman, "Type I and type II alcoholism: an update," Alcohol Health \& Research World, vol. 20, pp. 18-23, 1996.

[5] T. A. Wills, D. Vaccaro, and G. McNamara, "Novelty seeking, risk taking, and related constructs as predictors of adolescent substance use: an application of Cloninger's theory," Journal of Substance Abuse, vol. 6, no. 1, pp. 1-20, 1994.

[6] M. O. Howard, D. Kivlahan, and R. D. Walker, "Cloninger's tridimensional theory of personality and psychopathology: applications to substance use disorders," Journal of Studies on Alcohol, vol. 58, no. 1, pp. 48-66, 1997.

[7] K. Berglund, U. Berggren, C. Fahlke, and J. Balldin, "Selfreported health functioning in Swedish alcohol-dependent individuals: age and gender perspectives," Nordic Journal of Psychiatry, vol. 62, no. 5, pp. 405-412, 2008.

[8] K. J. Berglund, J. Balldin, U. Berggren, A. Gerdner, and C. Fahlke, "Childhood maltreatment affects the serotonergic system in male alcohol-dependent individuals," Alcoholism: Clinical and Experimental Research, vol. 37, no. 5, pp. 757-762, 2013.

[9] C. Fahlke, U. Berggren, K. J. Berglund et al., "Neuroendocrine assessment of serotonergic, dopaminergic, and noradrenergic functions in alcohol-dependent individuals," Alcoholism: Clinical and Experimental Research, vol. 36, no. 1, pp. 97-103, 2012.

[10] American Psychiatric Association, Diagnostic and Statistical Manual of Mental Disorders, American Psychiatric Association, Washington, DC, USA, 1st edition, 994.

[11] A. T. McLellan, H. Kushner, D. Metzger et al., "The fifth edition of the addiction severity index," Journal of Substance Abuse Treatment, vol. 9, pp. 199-213, 1992.

[12] C. Leonhard, K. Mulvey, D. R. Gastfriend, and M. Shwartz, "The Addiction Severity Index: a field study of internal consistency and validity," Journal of Substance Abuse Treatment, vol. 18, no. 2, pp. 129-135, 2000.

[13] B. E. Stöffelmayr, B. E. Mavis, and R. M. Kasim, "The longitudinal stability of the addiction severity index," Journal of Substance Abuse Treatment, vol. 11, no. 4, pp. 373-378, 1994.

[14] C. R. Cloninger, T. R. Przybeck, D. M. Svrakic, and R. D. Wetzel, The Temperament and Character Inventory (TCI): A Guide to Its
Development and Use, Center for Psychobiology of Personality, Washington University, St. Louis, Mo, USA, 1994.

[15] S. Brändström, S. Sigvardsson, P.-O. Nylander, and J. Richter, "The Swedish version of the Temperament and Character Inventory (TCI): a cross-validation of age and gender influences," European Journal of Psychological Assessment, vol. 24, no. 1, pp. 14-21, 2008.

[16] A. von Eye, Configural frequency analysis-Methods, models, and applications, Lawrence Erlbaum, Mahwah, NJ, USA, 2001.

[17] A. von Eye, C. Spiel, and P. K. Wood, "CFA models, tests, interpretation, and alternatives: a rejoinder," Applied Psychology: An International Review, vol. 45, no. 4, pp. 345-352, 1996.

[18] R. A. Zucker, "The four alcoholisms: a developmental account of the etiologic process," in Proceedings of the Nebraska Symposium on Motivation. Alcohol and Addictive Behaviors, P. C. Rivers, Ed., vol. 34, pp. 27-83, University of Nebraska Press, Lincoln, Neb, USA, 1987.

[19] R. A. Zucker, "Pathways to alcohol problems and alcoholism: A developmental account of the evidence for multiple alcoholisms and for contextual contributions to risk," in The Development of Alcohol Problems: Exploring the Biopsychosocial Matrix of Risk, R. Zucker, G. Boyd, and J. Howard, Eds., NIAAA Research Monograph No. 26, pp. 255-289, NIAAA, Rockville, Md, USA, 1994. 


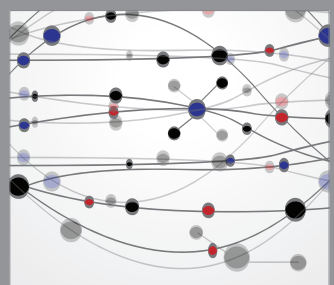

The Scientific World Journal
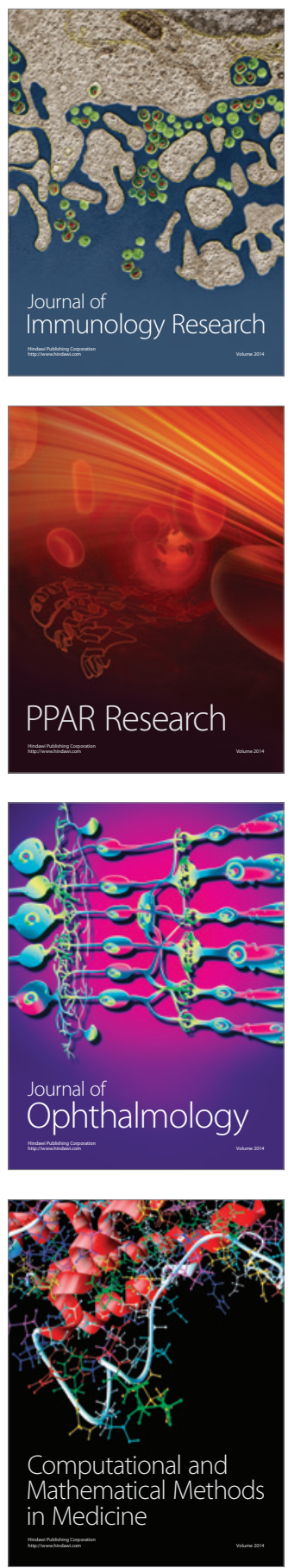

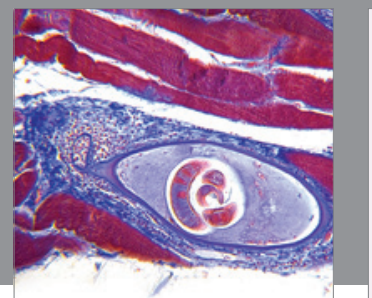

Gastroenterology

Research and Practice
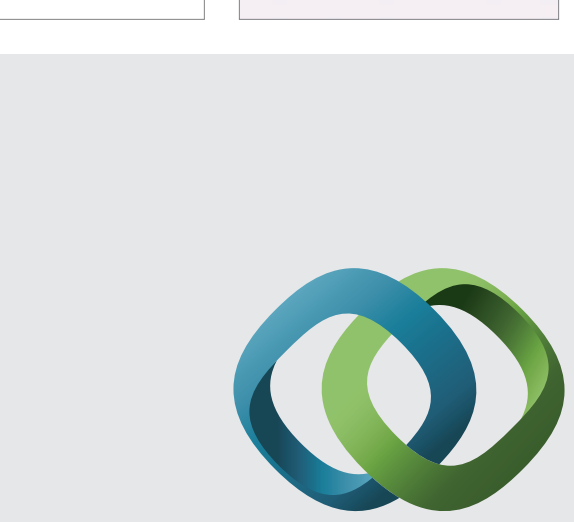

\section{Hindawi}

Submit your manuscripts at

http://www.hindawi.com
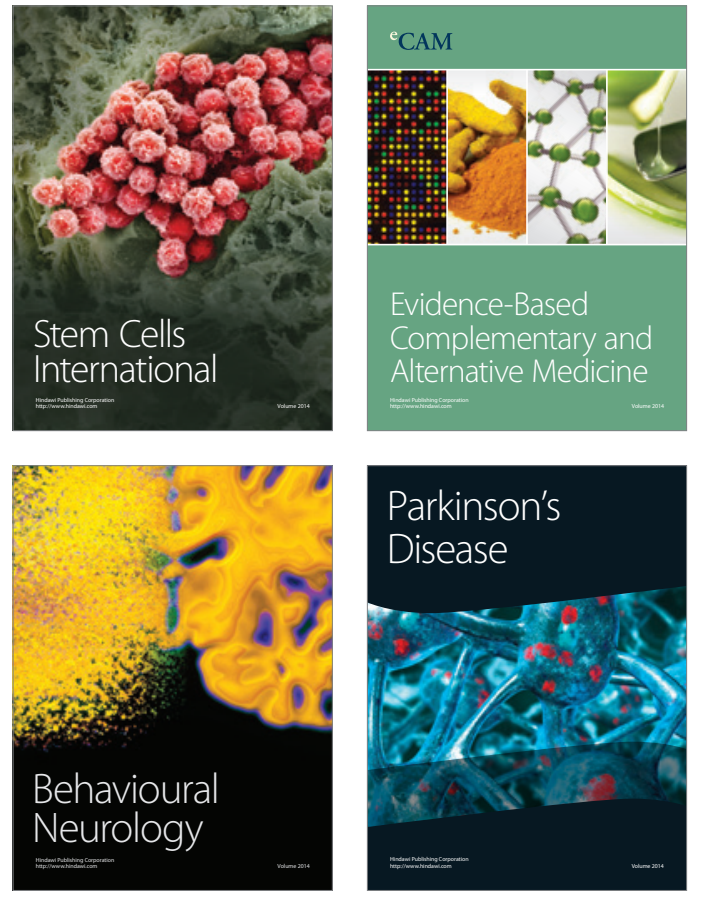
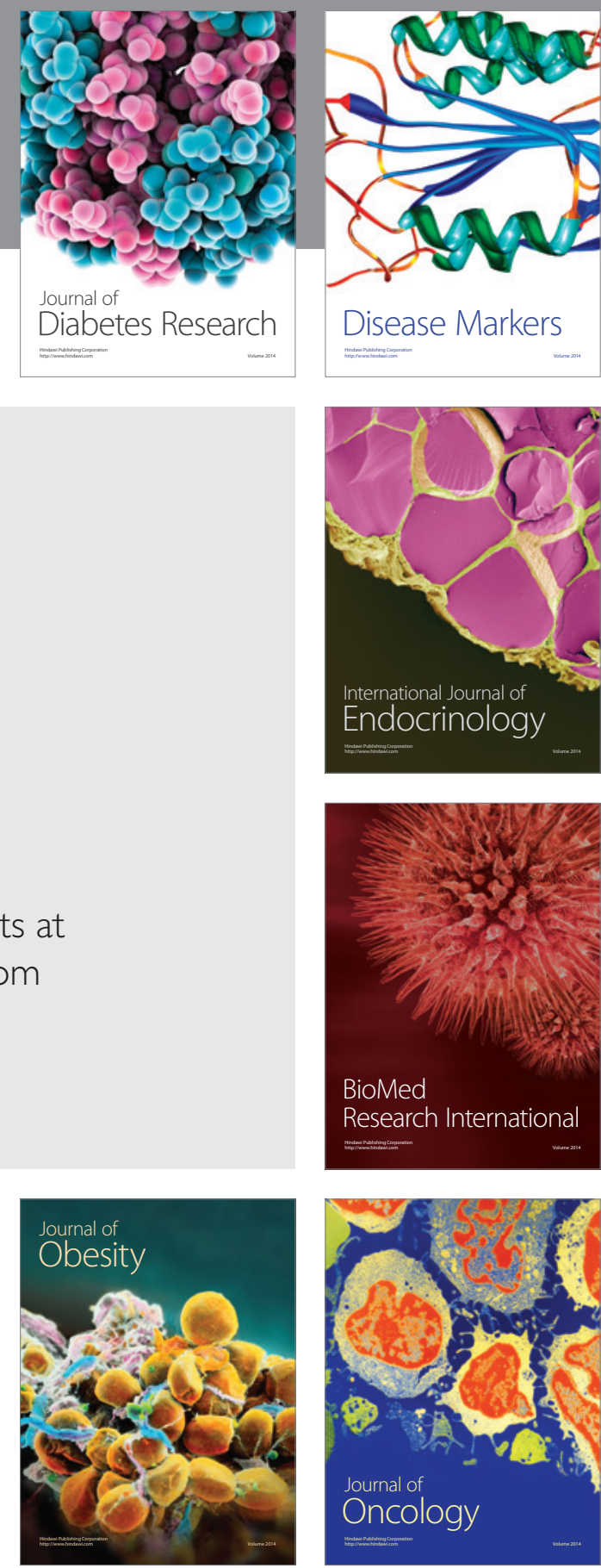

Disease Markers
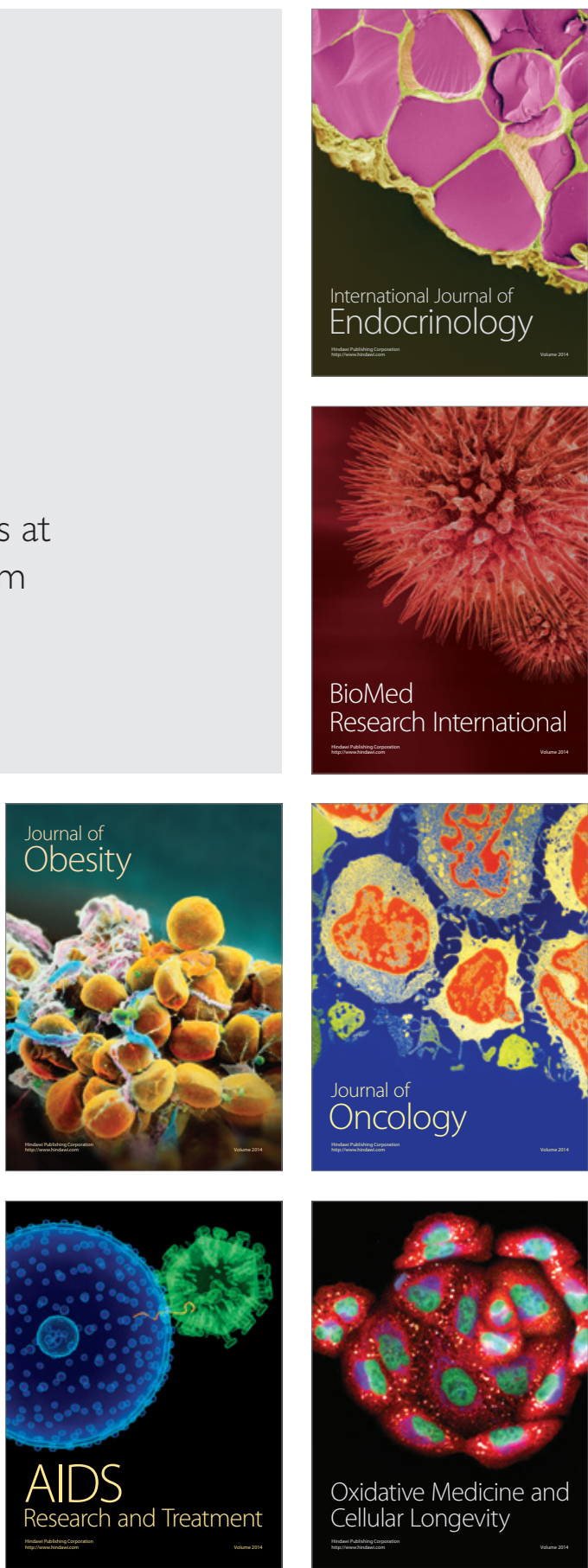